\title{
Identification of Bronze Workshops using p-XRF and ICP-MS in Angkor Thom, Cambodia
}

Nicole Little ${ }^{1}$ and Brice Vincent ${ }^{2}$

${ }^{1}$ Smithsonian Institution, United States, ${ }^{2}$ École française d'Extrême-Orient, United States

In 2012, archaeological teams associated with the Ecole française d'Extrême-Orient (EFEO) were able to uncover previously unknown bronze workshops at the ceremonial center of Angkor Thom in Siem Reap, Cambodia. Radiocarbon dating has confirmed the workshops were actively used during the 11th to 12th centuries at the height of Angkor civilization under King Jayavarman VII. Excavations for this project are now aimed at identifying the degree of metalworking (for both bronze sculptures and leaded roof tiles) at the ceremonial center of Angkor Thom during this important period.

As a result, 251 soil samples were taken from 64 soil probes (and several test pits) in 2016 from across the ceremonial complex for processing and analysis by inductively coupled plasma-mass spectrometry (ICP-MS) at the Smithsonian Museum Conservation Institute in Suitland, MD. While in the field, portable X-ray fluorescence ( $\mathrm{pXRF}$ ) was used to determine in-situ heavy metal content for each soil core at the depth most commonly associated with excavated bronze workshops (at $100 \mathrm{~cm}$ depth when possible). Because metals like $\mathrm{Cu}$ and $\mathrm{Pb}$ readily leach into surrounding soils ${ }^{1}, \mathrm{pXRF}$ can be an effective qualitative tool for assessing the likely locations for debris from metalworking kilns.

Before p-XRF analysis, soils were dried, ground to a powder, and weighed at $2.0 \mathrm{~g}$ for shipment to the US, and to reduce heterogeneity as much as possible. The homogenized soils were then placed in a cleaned HDPE sample cup for analysis. The instrument used was a Bruker Tracer III-V+ handheld XRF with a Rhodium source, operated at $40 \mathrm{kV} 30 \mathrm{uA}$ for 200 live seconds. P-XRF spectra and net counts (after background and overlap subtractions) were evaluated using Bruker Artax software to determine the efficacy of using p-XRF for heavy metal detection in soils. Once in the United States, soils were autoclaved at the Smithsonian Environmental Research Center, an APHIS-certified facility in Edgewater MD, per USDA requirements. Samples were then prepared for ICP-MS analysis using a modified version of the method described by Kennett et $\mathrm{al}^{2}$. They were then digested using a combination of concentrated nitric acid, heat, and pressure using a Milestone ETHOS ${ }^{\mathrm{TM}}$ UP microwave digestion system. Digested samples were diluted and analyzed for a range of elements on a GBC Optimass 9500 time-of-flight ICPMS. Because soils are too heterogeneous to properly quantify using $\mathrm{p}-\mathrm{XRF}$, all samples were precisely quantified by ICP-MS. P-XRF analysis was done on a subset of soil probe samples suspected to be at "workshop level", with p-XRF data being reported as net counts.

Preliminary ICP-MS results reveal concentrations of $\mathrm{Cu}$ and $\mathrm{Pb}$ in several areas in excess of $1000 \mathrm{ppm}$, far exceeding expected environmental levels. P-XRF was found to precisely predict locations of suspected bronze workshop activity across the site of Angkor Thom. Examples of six soil probes demonstrating elevated and trace levels of $\mathrm{Cu}$ (as quantified by ICP-MS) are shown in Table 1. Figure 1 shows XRF spectra for two of the characteristic soil probes (018-100 and 037-100), demonstrating the ability of p$\mathrm{XRF}$ to determine the presence/absence of a $\mathrm{Cu}$-enriched area of the site. The resulting presentation will further demonstrate how concentrations of $\mathrm{Cu}$ and other heavy metals are distributed spatially across the site of Angkor Thom. 
Table 1. ICP data in ppm showing cores with elevated $\mathrm{Cu}$, as expected, for those areas of the site with suspected workshop activity (on the left), versus cores with low $\mathrm{Cu}$. content on the right for areas without suspected workshop activity.

\begin{tabular}{|lccc|}
\hline Sample & $018-100$ & $031-100$ & $062-100$ \\
\hline $\mathrm{As}$ & 18.3 & 11.5 & 18.0 \\
\hline $\mathrm{Ba}$ & 121.5 & 60.5 & 86.1 \\
\hline $\mathrm{Cd}$ & 1.9 & 1.9 & 0.5 \\
\hline $\mathrm{Cu}$ & $\mathbf{3 1 7 2 . 2}$ & $\mathbf{2 1 3 5 . 8}$ & 1703.8 \\
\hline $\mathrm{Mg}$ & 852.1 & 402.1 & 448.8 \\
\hline $\mathrm{Mn}$ & 288.3 & 130.4 & 230.6 \\
\hline $\mathrm{Pb}$ & 295.0 & 167.5 & 531.9 \\
\hline $\mathrm{Rb}$ & 38.9 & 20.1 & 14.6 \\
\hline $\mathrm{Sr}$ & 27.4 & 10.0 & 10.6 \\
\hline $\mathrm{Zn}$ & 67.3 & 38.7 & 64.8 \\
\hline
\end{tabular}

\begin{tabular}{|l|c|c|c|}
\hline Sample & $017-100$ & $037-100$ & $055-100$ \\
\hline As & 4.3 & 2.3 & 7.4 \\
\hline $\mathrm{Ba}$ & 40.5 & 19.5 & 37.8 \\
\hline $\mathrm{Cd}$ & 0.2 & 0.5 & 0.3 \\
\hline $\mathrm{Cu}$ & 78.7 & 74.0 & 68.8 \\
\hline $\mathrm{Mg}$ & 292.5 & 192.4 & 242.5 \\
\hline $\mathrm{Mn}$ & 122.8 & 52.9 & 166.7 \\
\hline $\mathrm{Pb}$ & 95.9 & 15.8 & 41.8 \\
\hline $\mathrm{Rb}$ & 11.5 & 13.5 & 16.0 \\
\hline $\mathrm{Sr}$ & 7.5 & 5.2 & 5.6 \\
\hline $\mathrm{Zn}$ & 13.7 & 7.5 & 17.5 \\
\hline
\end{tabular}

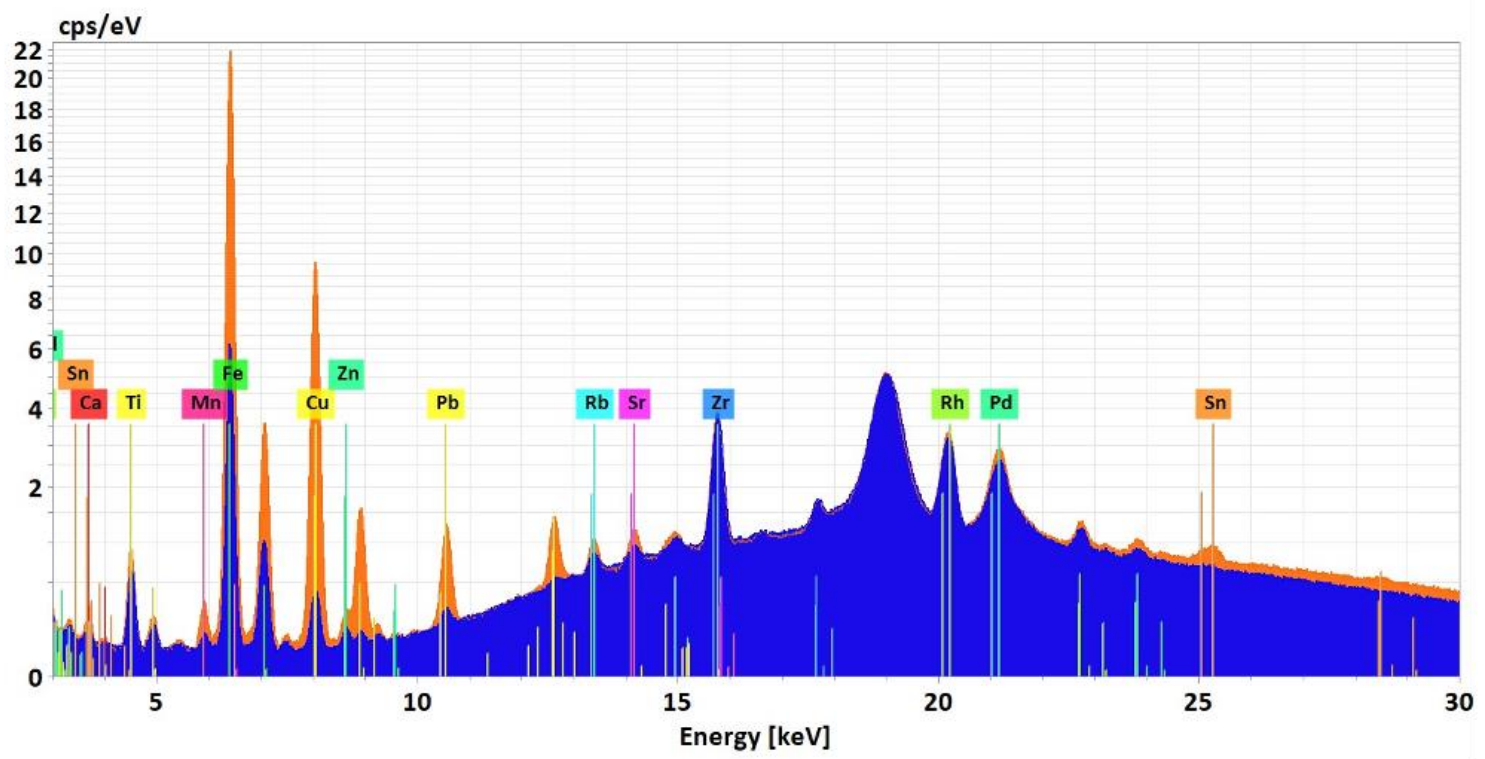

Figure 1. P-XRF spectra for 018-100 (orange) and 037-100 (blue) showing the difference in peak heights for $\mathrm{Cu}$ and $\mathrm{Pb}$ for an area with suspected workshop activity (018-100) versus one without (037-100). Spectra have been normalized to the Rh peak.

\section{References}

1. Kennett et al, Journal of Archaeological Science, 29 (2002) p. 443.

2. Dube et al, Polish Journal of Environmental Studies 10, No. 1 (2001) p.1-10. 